\title{
Editorial Note: Security and Privacy of Multimedia Big Data in Mobile and Cloud Computing
}

Multimedia Tools and Applications gratefully acknowledges the editorial work of the scholars listed below on the special issue entitled, "Security and Privacy of Multimedia Big Data in Mobile and Cloud Computing."

Of 33 papers submitted to this issue, only 11 were eventually accepted after a stringent peer-review process.

Dr. B. B. Gupta (Corresponding Guest Editor)

National Institute of Technology Kurukshetra, India

Email: bbgupta@nitkkr.ac.in

\section{Dr. Shingo Yamaguchi}

Yamaguchi University, Japan

Email: shingo@yamaguchi-u.ac.jp

\section{Dr. Dharma P. Agrawal}

OBR Distinguished Professor

University of Cincinnati, Cincinnati, USA

Email: dpa@cs.uc.edu 